\title{
INFLUÊNCIA DO TEOR DE ÁGUA, DA EMBALAGEM E DAS CONDIÇÕES DE ARMAZENAMENTO NA QUALIDADE DE SEMENTES DE MARACUJÁ ẢMARELO ${ }^{1}$
}

\author{
PAULO HENRIQUE ARAGÃO CATUNDA ${ }^{2}$, HENRIQUE DUARTE VIEIRA ${ }^{3}$, ROBERTO FERREIRA DA SILVA ${ }^{4}$, \\ SHEILA CRISTINA PRUCOLLI POSSE ${ }^{5}$
}

\begin{abstract}
RESUMO - A influência dos teores de água ( 8 e $10 \%$ b.u.), da embalagem ('pouch' de alumínio flexível e saco de papel multifoliado) e do ambiente de armazenamento (laboratório, com a temperatura variando de $21-29^{\circ} \mathrm{Ce} 50-80 \%$ UR e duas condições controladas $18^{\circ} \mathrm{C} / 24 \% \mathrm{UR} \mathrm{e} 4^{\circ} \mathrm{C} /$ $60 \%$ UR) sobre a qualidade das sementes de maracujá amarelo foram avaliadas neste trabalho. As sementes acondicionadas nas diferentes embalagens foram expostas aos três ambientes para serem avaliadas, bimestralmente, tendo sido determinado: o teor de água, a germinação e o vigor das sementes, pelo teste de envelhecimento acelerado. Os resultados indicaram que as sementes acondicionadas com teor de água de $10 \%$ apresentaram uma redução drástica na germinação, quando acondicionadas em embalagem impermeável em condição de laboratório, enquanto o ambiente sob temperatura de $4{ }^{\circ} \mathrm{C}$ e $60 \%$ UR foi o mais eficiente para preservar a viabilidade das sementes, independente do tipo de embalagem.
\end{abstract}

Termos para indexação: semente, maracujá, germinação, vigor, armazenamento.

\section{INFLUENCE OF MOISTURE CONTENT, PACKAGING AND STORAGE ENVIRONMENT ON YELLOW PASSION FRUIT SEED QUALITY}

\begin{abstract}
This experiment was designed to verify the influence on yellow passion fruit seed quality of 8 and $10 \%$ moisture content (wet basis), package type ( flexible aluminum pouch and paper bag) and the storage environment: laboratory room, temperature varying between $21-29^{\circ} \mathrm{C}$ and relative humidity between $50-80 \%$, and two controlled conditions, $18^{\circ} \mathrm{C} / 24 \% \mathrm{RH}$ and $4^{\circ} \mathrm{C} /$ $60 \% \mathrm{RH}$. The seeds placed in the different packaging were stored in the three different environments for bimonthly evaluation. The following determinations were carried out: seed moisture content, germination and the vigor determined by the accelerated aging test. The tests indicated that seeds conditioned with $10 \%$ moisture content presented a drastic reduction in germination, when placed in impermeable packaging in laboratory room conditions, while the treatment with temperature of $4^{\circ} \mathrm{C}$ and $60 \% \mathrm{RH}$ showed the best results to preserve the seed viability, regardless of the type of packaging.

Index terms: seed, passion fruit, germination, vigor, storage.
\end{abstract}

\section{INTRODUÇÃO}

O maracujazeiro (Passiflora edulis Sims f. flavicarpa Deg.) é uma fruteira cuja propagação é feita normalmente por sementes, razão pela qual torna-se importante conhecer a sua capacidade de conservação, além de permitir um manejo

\footnotetext{
${ }^{1}$ Aceito para publicação em 10.06.2003.

${ }^{2}$ Eng $^{\circ}$ Agr $^{\circ}$, MS., Laboratório de Fitotecnia, Campos dos Goytacazes, RJ; e-mail: catunda@uenf.br

${ }^{3}$ Eng $^{\circ}$ Agr $^{\circ}$, DS., Prof. da UENF, Lab. de Fitotecnia, Campos dos Goytacazes, RJ; e-mail: henrique@uenf.br
}

mais adequado de germoplasma (Oliveira et al.,1984). Além disto, as plantas de maracujazeiro originárias de sementes são mais vigorosas e precoces que aquelas provenientes de enxertia (Maldonado, 1991).

Ainda são escassas as pesquisas relacionadas com Tecnologia de Sementes de espécies frutíferas no Brasil. As próprias Regras para Análise de Sementes (Brasil, 1992) que

\footnotetext{
${ }^{4}$ Eng $^{\circ} \mathrm{Agr}^{\circ}, \mathrm{PhD}$, Prof. Titular da UENF, Lab. de Fitotecnia, Campos dos Goytacazes, RJ; roberto@uenf.br

${ }^{5}$ Eng $^{\circ}$ Agr $^{\circ}$, MS., Laboratório de Fitotecnia, Campos dos Goytacazes, RJ; sheila@uenf.br
} 
prescrevem os procedimentos ideais para análise de pelo menos 200 espécies de sementes, apresentam omissões e limitações quando se refere às espécies frutíferas. A dificuldade é ainda maior pelo fato de que muitas espécies frutíferas apresentam sérios problemas de conservação e germinação das sementes.

Muitos autores têm relatado que a preservação do poder germinativo das sementes de maracujá amarelo é relativamente curta, não sendo superior a um ano (Pizza Júnior, 1966). Pesquisas mais recentes têm mostrado que a preservação da germinação destas sementes é variável de acordo com as condições de armazenamento (São José, 1987; Nakagawa et al., 1991), e tem sido maior em condições onde o ambiente é controlado do que em ambiente natural (Geraldi Junior, 1974; Thai, 1977; Almeida, 1985; São José, 1987; Becwar et al., 1983).

Portanto, o conhecimento de métodos apropriados para a conservação de sementes de maracujá amarelo é de grande importância em virtude das plantações apresentarem um reduzido período de vida útil, aliado ao fato de grande parte dos fruticultores utilizar sementes de suas próprias lavouras, obtidas, muitas vezes, sem critérios rigorosos de seleção. Outro fator a considerar é o elevado preço de sementes selecionadas de maracujá utilizadas em plantios com alta tecnologia, o que justifica determinar e conhecer as condições ideais para preservar a qualidade destas sementes.

Este trabalho foi desenvolvido com o objetivo de avaliar o efeito do teor de água da semente, do tipo de embalagem e do ambiente de armazenamento na qualidade fisiológica das sementes de maracujá amarelo, armazenadas por um período de dez meses.

\section{MATERIAL E MÉTODOS}

As sementes de maracujá (Passiflora edulis Sims f. flavicarpa Deg.) utilizadas neste trabalho foram obtidas de frutos provenientes de um pomar instalado no município de Campos dos Goytacazes-RJ, onde foram selecionados frutos completamente maduros, de plantas sadias, livres de pragas e doenças, seguindo-se os procedimentos recomendados por Ruggiero (1998).

As sementes, após retiradas dos frutos, foram extraídas da polpa por abrasão sobre uma peneira de arame com o auxílio de cal virgem $(\mathrm{CaO})$, na proporção de $50 \mathrm{~g} / \mathrm{Kg}$ de polpa. Em seguida as sementes foram lavadas e submetidas à secagem em uma estufa de ventilação forçada à temperatura ambiente até que alcançassem o teor de umidade desejável para o estudo. Após a secagem, os arilos remanescentes nas sementes foram removidos por fricção manual.

As sementes com o teor de umidade de 8 e $10 \%$ foram acondicionadas em dois tipos de embalagens, 'pouch' de alumínio flexível e saco de papel multifoliado.

Para cada tratamento, no início e durante os períodos de armazenamento correspondentes, foi determinado o teor de umidade das sementes, pela retirada de duas amostras de aproximadamente $4,0 \mathrm{~g}$, as quais depois de pesadas, foram transferidas para estufa, regulada a $105 \pm 3^{\circ} \mathrm{C}$ por um período de 24 horas (Brasil, 1992).

As condições de armazenamento foram as seguintes: refrigerador, onde a temperatura foi regulada para $4^{\circ} \mathrm{C}$ e $60 \%$ UR, câmara regulada à temperatura de $18^{\circ} \mathrm{C}$ e $24 \%$ UR e armazenamento em ambiente de laboratório, monitorado por um termohigrógrafo digital, modelo Specware ${ }^{\mathrm{TM}} 4.1$, que registrou os valores da temperatura e umidade relativa diárias durante todo o período do armazenamento. O período de armazenamento teve duração de dez meses, sendo que, a cada dois meses, foram realizadas as respectivas determinações e testes para avaliação da qualidade das sementes: teor de água, germinação e vigor.

Para realização do teste de germinação (TG), utilizaram-se caixas gerbox, onde as sementes foram dispostas sobre 3 folhas de papel germiteste umedecidas com $12 \mathrm{ml}$ de água destilada, cobertas por uma quarta folha, que foi retirada posteriormente, 14 dias após o início do teste. As caixas gerbox contendo 50 sementes foram transferidas para uma câmara de germinação do tipo BOD, regulada à temperatura alternada de $20-30^{\circ} \mathrm{C}$ e $16-8$ horas de escuro-luz, respectivamente.

No teste de envelhecimento acelerado, para cada tratamento, quatro repetições de 200 sementes foram distribuídas, uniformemente, sobre telas de arame colocadas no interior das caixas gerbox contendo, ao fundo, $40 \mathrm{ml}$ de água destilada. As caixas foram transferidas para uma câmara regulada à temperatura de $42^{\circ} \mathrm{C}$, onde permaneceram por um período de 60 horas. Após este período, foram retiradas 50 sementes de cada repetição, colocadas para germinar seguindo os mesmos procedimentos do teste de germinação.

Os experimentos seguiram o delineamento inteiramente casualizado com 4 repetições, num esquema fatorial, em parcelas subdivididas no tempo, $2 \times 2 \times 3 \times 6$, sendo dois teores de umidade $(8$ e $10 \%)$, dois tipos de embalagem (impermeável e semi-permeável), três ambientes de armazenamento (refrigerador, câmara fria e ambiente de laboratório) e, na subparcela, seis períodos de armazenamento $(0,2,4,6,8,10$ 
meses). Os dados obtidos em \%, foram transformados em arcoseno $(\% \mathrm{G} / 100)^{1 / 2}$ e a análise dos dados processada por regressão polinomial.

\section{RESULTADOS E DISCUSSÃO}

Na Figura $1(a, b, c$,$) pode-se verificar que as sementes$ acondicionadas em embalagens impermeáveis, praticamente, não apresentaram variação em seu teor de água nos ambientes testados, como era esperado. Por outro lado as sementes acondicionadas em embalagem permeável, alcançaram a umidade de equilíbrio de acordo com as características de cada ambiente de armazenamento, em torno de $9 \%$, para o ambiente de laboratório e refrigerador, variando entre $4 \% \mathrm{e}$ $6 \%$, em câmara fria a $18^{\circ} \mathrm{C}$ e $24 \% \mathrm{UR}$, certamente, devido à baixa umidade relativa do ar deste ambiente. De acordo com Carvalho e Nakagawa (2000), mudanças na temperatura e umidade relativa do ar provocam constantes ajustes no teor de água das sementes armazenadas em embalagens permeáveis ao vapor de água.

Em ambiente de laboratório, as sementes acondicionadas em embalagem impermeável com teor de água de $8 \%$ mostraram um decréscimo na germinação até seis meses de armazenamento, tendo mantido a porcentagem de germinação acima de $50 \%$, conservando-se melhor do que aquelas acondicionadas com teor de água de $10 \%$, as quais apresentaram um decréscimo linear na germinação, até perder completamente a viabilidade próximo aos 9 meses de armazenamento (Figura 2a). Realmente as sementes de maracujá com teor de água inicial de $10 \%$ não devem ser acondicionadas em embalagem impermeável sob condições naturais conforme foi observado por Justice e Bass (1978), citados por Freitas (1997). Segundo esses autores, para o armazenamento seguro da maioria das espécies de sementes consideradas ortodoxas, neste tipo de embalagem, o teor de água das sementes deve-se manter na faixa de 3 a $7 \%$.

$\mathrm{Na}$ Figura $2 \mathrm{~b}$ pode-se observar que a germinação das sementes armazenadas em condições de laboratório, acondicionadas em embalagem permeável, apresentou comportamento diferenciado ao longo do armazenamento, sendo que após o sexto mês de armazenamento aquelas sementes com teor de umidade de $8 \%$ mostraram um decréscimo mais acentuado na germinação, enquanto as sementes acondicionadas com teor de água de $10 \%$ mantiveram a germinação acima de $60 \%$ durante os dez meses de armazenamento.

Os resultados obtidos contradizem aqueles encontrados por Almeida (1987), que observou que o armazenamento em condições de ambiente após doze meses foi prejudicial à viabilidade das sementes em todos os tratamentos, quando a germinação alcançou o valor zero. Thai (1977) também verifi-
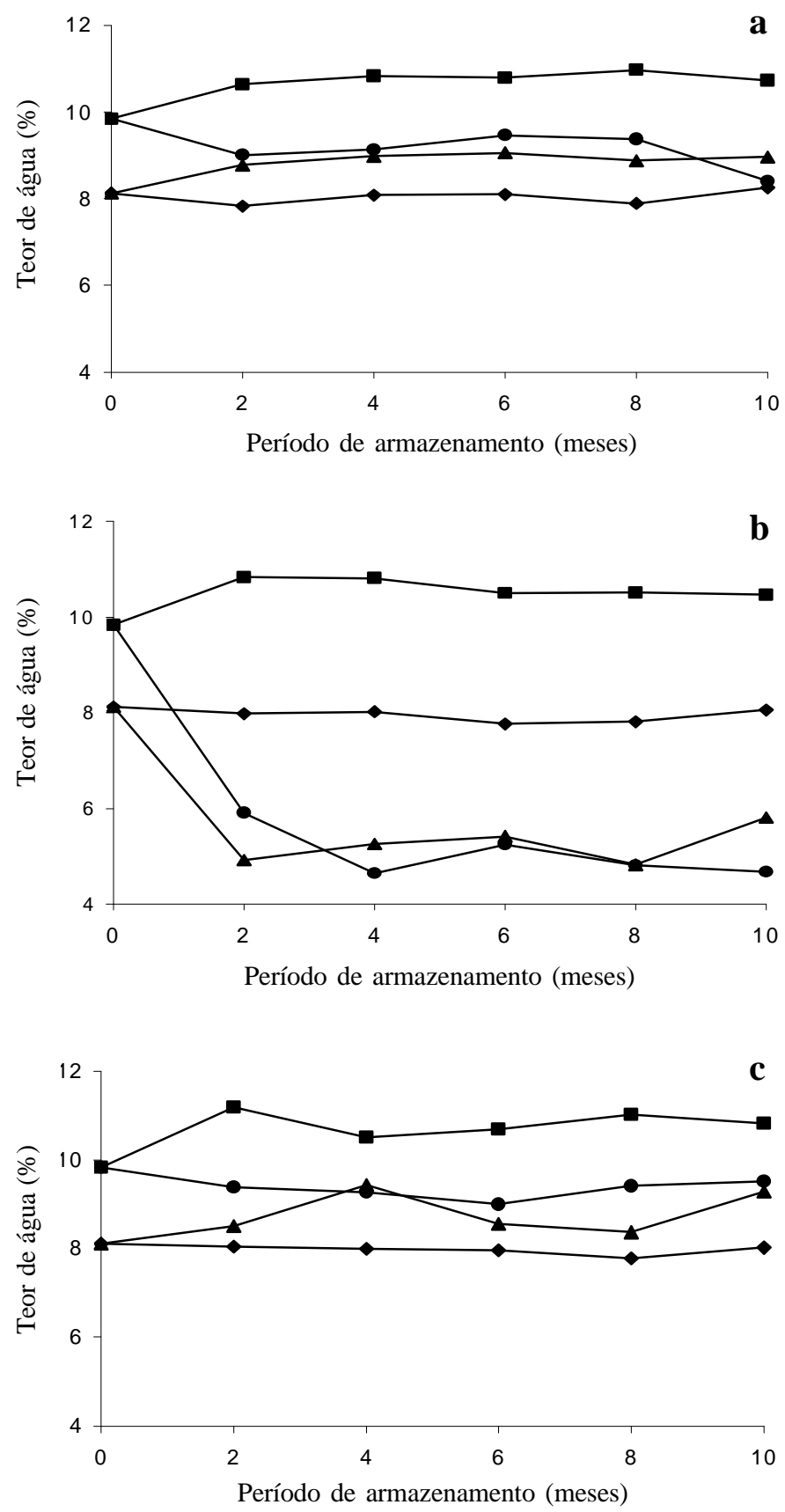

$\longrightarrow$ embalagem impermeável, $8 \% \longrightarrow$ embalagem impermeável, $10 \%$ $\multimap$ embalagem permeável, $8 \% \quad \longrightarrow$ embalagem permeável, $10 \%$

FIG. 1. Efeito da umidade inicial das sementes do tipo de embalagem e do período de armazenamento, sobre teor de água das sementes de maracujá armazenadas em ambiente de laboratório (a), câmara fria $18^{\circ} \mathrm{C}$ e $24 \%$ UR (b) e refrigerador $4^{\circ} \mathrm{C}$ e $60 \% \mathrm{UR}$ (c). 

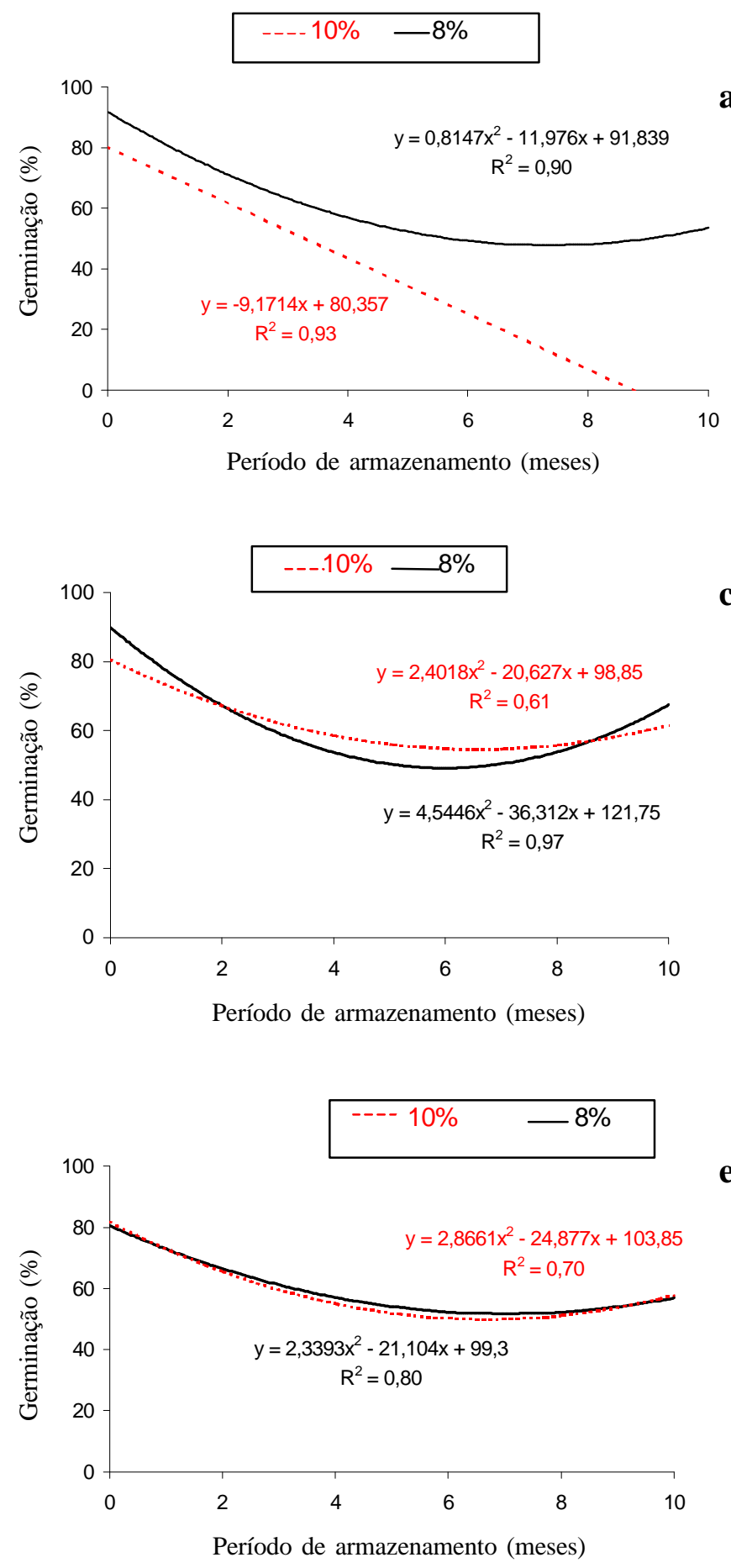

$\mathbf{a}$

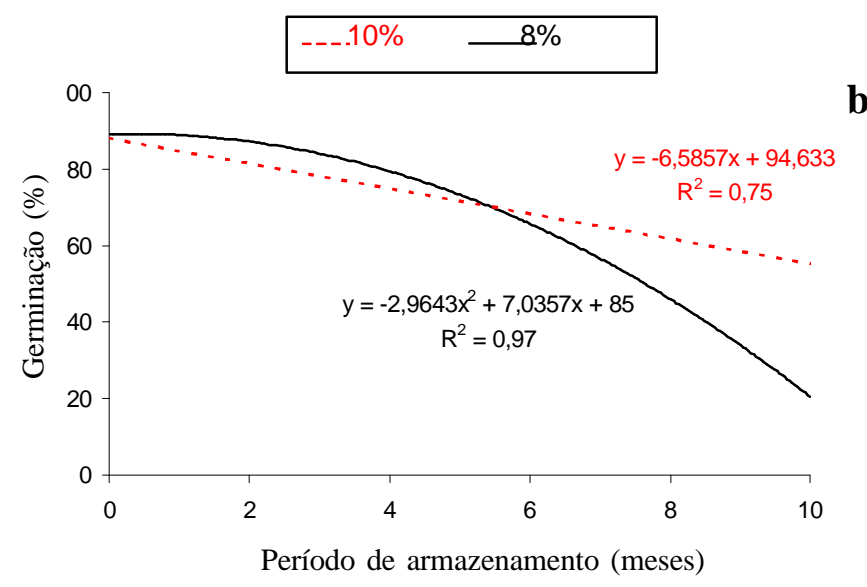

c

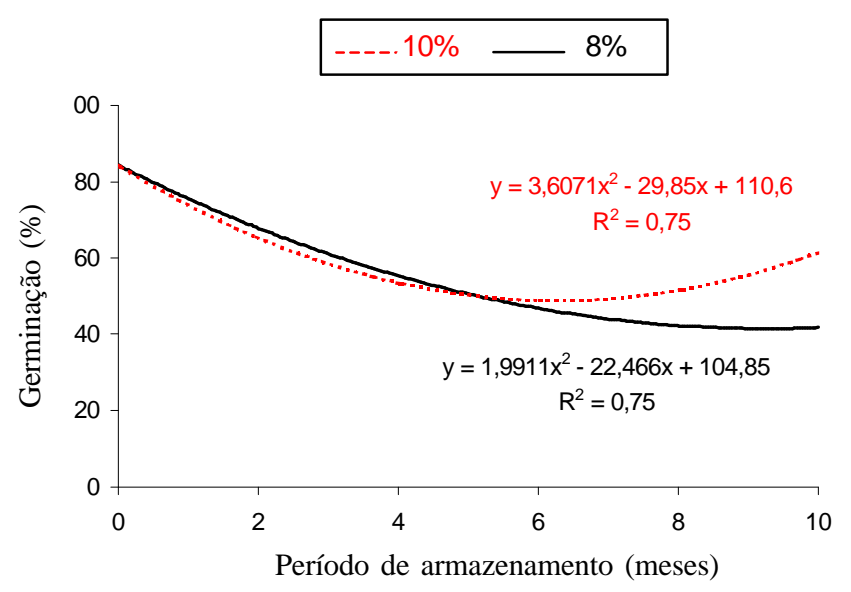

e

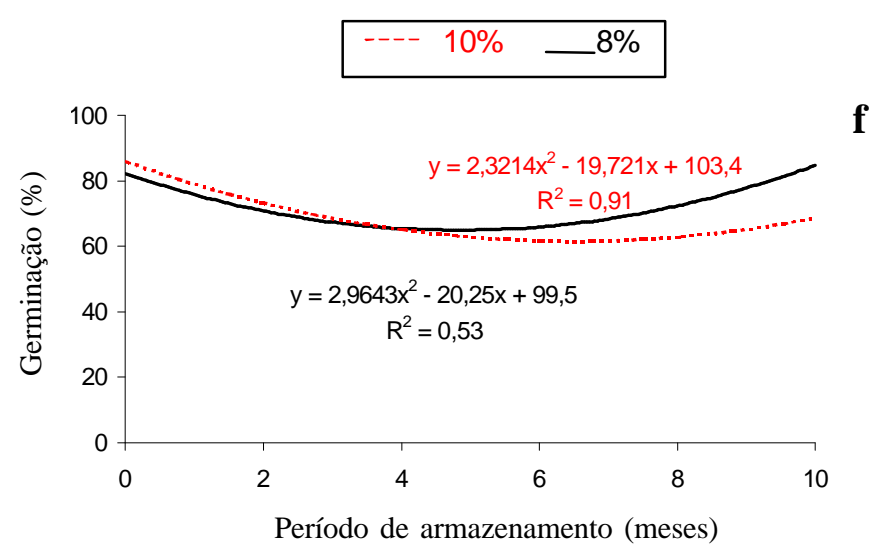

FIG. 2. Germinação de sementes de maracujá amarelo, acondicionadas em embalagem impermeável (a,c,e) e permeável (b,d,f), armazenadas em ambiente de laboratório $(a, b)$, câmara fria $\left(18^{\circ} \mathrm{C}, 24 \% \mathrm{UR}\right)(\mathrm{c}, \mathrm{d})$ e refrigerador $\left(4^{\circ} \mathrm{C}, 60 \% \mathrm{UR}\right)(\mathrm{e}, \mathrm{f})$. 
cou que sementes de maracujá armazenadas em condições de ambiente perderam toda a viabilidade após dez meses de armazenamento.

Em câmara regulada a $18^{\circ} \mathrm{C}$ e $24 \%$ UR, (Fig. 2 c e 2 d), observou-se uma resposta quadrática da germinação das sementes sendo que, ao final de 10 meses, a germinação ainda permaneceu acima de $45 \%$, para os teores de umidade de 8 e $10 \%$ em ambas embalagens.

A germinação superior a $45 \%$ ao final do período de armazenamento em câmara fria, comparado com o ambiente de laboratório pode, ser explicado pelas inferências de Harrington (1959), que preconiza que, para se conservar o poder germinativo e o vigor das sementes, é necessário, dentro de certos limites, mantê-las em ambiente frio e seco.

$\mathrm{Na}$ Figura 1b, observa-se que sementes acondicionadas em embalagem permeável, alcançaram teor de água entre $4 \%$ e 6\% após o segundo mês de armazenamento, teor este desejável para preservar a viabilidade das sementes. Constatou-se que, estas sementes que apresentavam baixos teores de umidade, não tiveram seu poder germinativo comprometido (Figura 2d), o que corrobora com os resultados obtidos por Becwar et al. (1983), que determinaram o limite mínimo de $2 \%$ de teor de água para que sementes de maracujá mantenham sua viabilidade. Este comportamento evidencia a característica típica de semente ortodoxa.

Pode-se observar que em refrigerador (Figura 2e, 2f) tanto para embalagem impermeável quanto para permeável, obtiveram-se os maiores valores de germinação para sementes de maracujá ao final do período de armazenamento, concordando com Lima et al. (1991), que obtiveram os melhores resultados de manutenção de viabilidade quando as sementes foram acondicionadas em lata, armazenadas em refrigerador.

Os resultados observados na Figura $2 \mathrm{f}$ estão de acordo com Almeida (1987) e Medina (1980), que verificaram o aumento da germinação das sementes de maracujá amarelo, após seis e 12 meses de armazenamento respectivamente. $\mathrm{O}$ que poderia ser atribuído à superação de um provável estado de dormência das sementes.

$\mathrm{O}$ refrigerador mantém uma temperatura de $4^{\circ} \mathrm{C}$, mas têm como limitação apresentar alta umidade relativa, o que resultou em aumento do teor de água das sementes acondicionadas em embalagem permeável (Fig 1c), entretanto para sementes de maracujá, nas condições deste experimento não propiciou efeito negativo na germinação.

Na Figura 3 (a,b,c,d,e,f) observam-se os resultados de vigor, pelo teste de envelhecimento acelerado. Sementes ar- mazenadas em condições de laboratório, acondicionadas em embalagem impermeável, com teores de água de $8 \%$ e $10 \%$ (Fig. 3a), tiveram comportamento similar entre si, sendo que as sementes acondicionadas com teor de água de $8 \%$, mantiveram, aos 10 meses de armazenamento, porcentagem de germinação acima de $20 \%$, enquanto as sementes acondicionadas com teor de água de $10 \%$ perderam completamente a viabilidade no oitavo mês de armazenamento. $\mathrm{O}$ teor de umidade das sementes não foi adequado para o acondicionamento em embalagem impermeável, resultando na aceleração do processo de deterioração, principalmente, nas sementes com teor de água de $10 \%$. Além disso, as variações da temperatura e da umidade relativa do ar, observadas no laboratório $\left(21,5^{\circ} \mathrm{C}\right.$ a $29^{\circ} \mathrm{C}$ e $50 \%$ a $80 \%$ UR), certamente, contribuíram para a redução no vigor das sementes.

$\mathrm{Na}$ Figura $3 \mathrm{~b}$ observa-se que as sementes acondicionadas, em embalagem permeável, com teor de água de $10 \%$, apresentaram aos dez meses de armazenamento vigor, acima de $40 \%$, enquanto as sementes acondicionadas com teor de água de $8 \%$ chegaram, ao fim do armazenamento, com vigor significativamente menor. Este decréscimo no vigor pode ser atribuído à umidade das sementes, juntamente com a variação de temperatura e da umidade do ambiente de laboratório.

No ambiente de laboratório, as sementes acondicionadas em embalagem impermeável, com teor de água de $8 \%$, apresentaram vigor superior às sementes acondicionadas com $10 \%$ de umidade, ao longo do período de armazenamento.

Em Câmara fria, as sementes acondicionadas em embalagem permeável (Fig. 3d), com teor de água de $10 \%$ mostraram uma ligeira superioridade no vigor em comparação às sementes acondicionadas com teor de água de $8 \%$ e ainda se mostraram superiores às sementes acondicionadas em embalagem de pouch de alumínio (Fig. 3c), evidenciando que mesmo nesta condição de armazenamento a embalagem impermeável foi inadequada para o acondicionamento das sementes de maracujá amarelo com 8 e 10\% de umidade.

$\mathrm{Na}$ figura $3 \mathrm{e}$ nota-se que as sementes acondicionadas em embalagem impermeável, com teor de água de $10 \%$ apresentaram vigor superior àquelas sementes acondicionadas com teor de água de $8 \%$ ao longo dos 10 meses de armazenamento. De acordo com Lima (1991), o decréscimo de vigor verificados nas sementes de maracujá amarelo, a partir do segundo mês, em ambiente de refrigerador, pode ser atribuído a consequiências naturais do processo de deterioração das sementes.

Na figura $3 \mathrm{f}$ observa-se que não houve diferença no comportamento do vigor, em sementes com 8 e $10 \%$ de umidade 

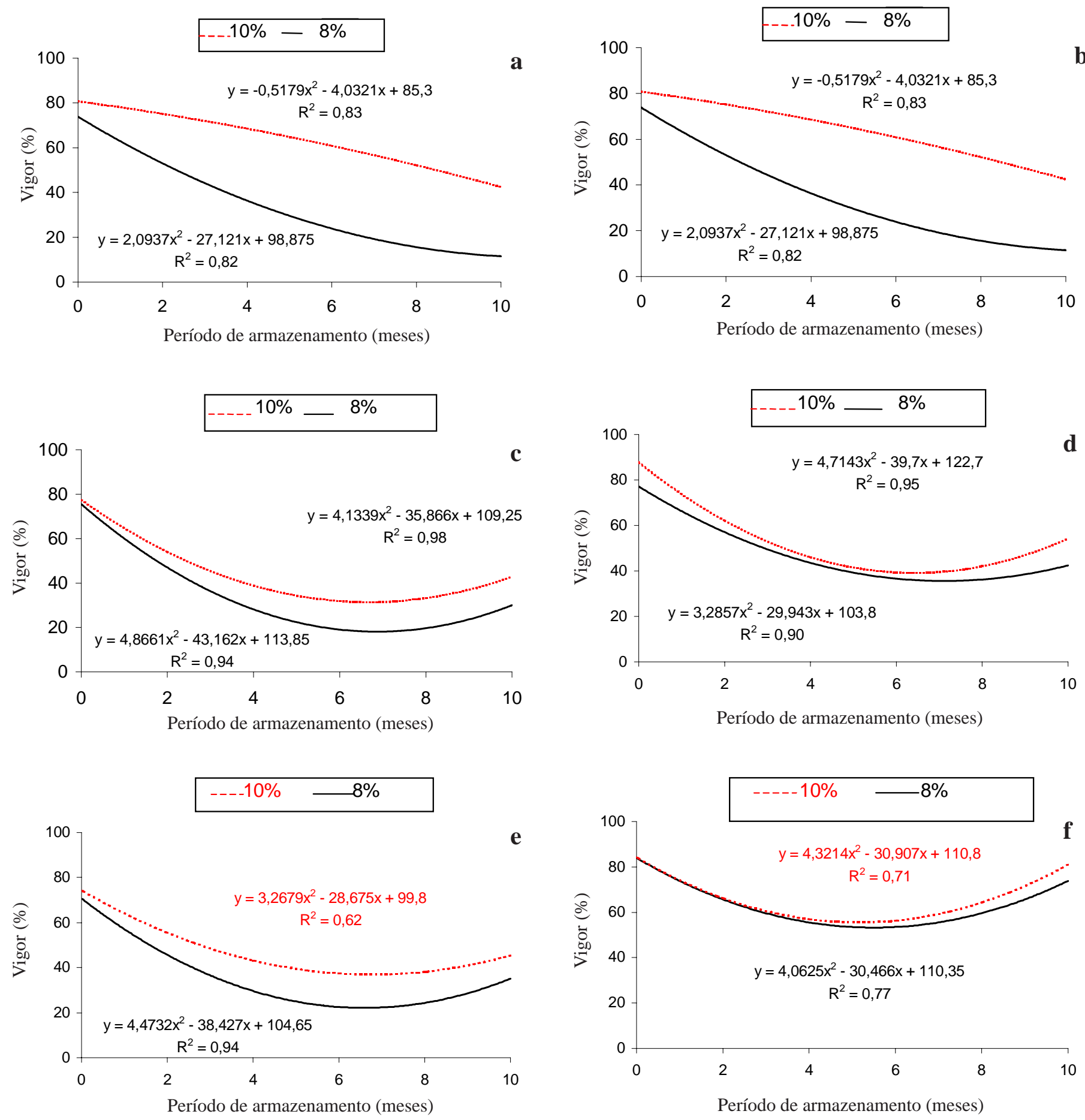

FIG. 3. Vigor de sementes de maracujá amarelo, acondicionadas em embalagem impermeável (a,c,e) e permeável (b,d,f), armazenadas em ambiente de laboratório (a,b), câmara fria $\left(18^{\circ} \mathrm{C}, 24 \% \mathrm{UR}\right)(\mathrm{c}, \mathrm{d})$ e refrigerador $\left(4^{\circ} \mathrm{C}, 60 \% \mathrm{UR}\right)$ (e,f). 
apesar das sementes com $10 \%$ mostrarem pequena superioridade em relação às sementes com $8 \%$ de umidade a partir do quarto mês de armazenamento.

De acordo com Lima, (1991) o ambiente de refrigerador também foi o mais apropriado para preservar o vigor das sementes de maracujá. A germinação, em ambiente de refrigerador, mostrou um ligeiro acréscimo, a partir do sexto mês, o que poderia, segundo o mesmo autor, ser explicado pela degradação de algum composto inibidor da germinação, remanescente nas sementes.

\section{CONCLUSÕES}

$\mathrm{O}$ ambiente de refrigerador $\left(4^{\circ} \mathrm{C}\right.$ e $\left.60 \% \mathrm{UR}\right)$, foi o mais apropriado para a preservação da viabilidade das sementes de maracujá amarelo por um período de 10 meses de armazenamento, independente do tipo de embalagem utilizada;

Em condição de laboratório, a embalagem impermeável se mostrou inadequada para o armazenamento de sementes de maracujá amarelo com teor de água de 8 e 10\%;

$\mathrm{O}$ comportamento germinativo das sementes de maracujá amarelo acondicionadas em embalagem permeável em câmara fria, não foi prejudicado em razão das sementes terem atingido valores de teor de água entre 4 e 6\%;

Após 10 meses de armazenamento, a melhor preservação do vigor ocorreu nas sementes de maracujá amarelas acondicionadas em embalagem permeáveis e mantidas em refrigerador.

\section{REFERÊNCIAS}

Almeida, A.M. Maturação e qualidade fisiológica de sementes de maracujá amarelo (Passiflora edulis Sims f. flavicarpa Deg.). 1985. 91f. Tese ( Mestrado) - Universidade do Estado de São Paulo, Botucatu.

Almeida, A.M.; Nakagawa, J.; Almeida, R.M. Efeito do armazenamento na germinação de sementes de maracujá amarelo de diferentes estádios de maturação. Experimento I. In: CONGRESSO BRASILEIRO DE FRUTICULTURA, 9., 1987, Campinas. Campinas: Sociedade Brasileira de Fruticultura, 1988. p.603-608p.

Becwar, M.R.; Stanwood, P.C.; Leonhardt, K.W. Dehydratation effects on freezing characterístics and survival in liquid nitrogen of desiccation-tolerant and desiccation-sensitive seeds. Journal
American Society Horticulture Science, v.108, n.4, p.613-618, 1983.

Brasil. Ministério da Agricultura e Reforma Agrária. Regras para análise de sementes. Brasília: SNDA/DNDV/CLAV,1992. $365 \mathrm{p}$.

CARVALHO, N.M.; NAKAGAWA, J. Sementes: ciência, tecnologia e produção. 4.ed. Jaboticabal: FUNEP, 2000. 588p.

Freitas, G.B. Propagação, florescimento, frutificação e produção da gravioleira (Annona muricata L.). 1997. 87f. Tese (Doutorado) - Universidade Federal de Viçosa, Viçosa.

Geraldi Junior, G. Estudo da germinação de sementes de maracujá amarelo (Passiflora edulis Sims f. flavicarpa Deg.) armazenado sob duas diferentes condições. 1974. 22f. Trabalho (Graduação) Faculdade de Ciências Agrárias e Veterinárias de Jaboticabal, Jaboticabal.

Harrington, J.F. Drying, storing, and packaging seeds to maintain germination and vigor. Proceedings Short Course Seedsmen, p.89108, 1959.

Lima, D. et al. Efeito de recipientes e de dois ambientes de armazenamento sobre a germinação e vigor de sementes de maracujá amarelo (Passiflora edulis Sims f. flavicarpa Deg.). Revista brasileira de fruticultura, Cruz das Almas, v.13, n.2, p. 27-32, 1991.

Maldonado, J.F.M. Utilização de porta-enxertos do gênero Passiflora para maracujazeiro amarelo (Passiflora edulis SIMS f. flavicarpa Deg.) Revista brasileira de fruticultura, Cruz das Almas, v.13, n.2, p.51-54,1991.

Medina, J.C. Maracujá: da cultura ao processamento e comercialização. ITAL: São Paulo, 1980. 207p.

Nakagawa, J.; Cavariani, C.; Amaral, W.A.N. Armazenamento de sementes de maracujá amarelo. Revista brasileira de sementes, Brasília-DF, v.13, n.1, p.77-80, 1991.

Oliveira, J.C.; Sader, R.; Zampieri, R.A. Efeito da idade sobre a emergência e vigor de sementes de maracujá-amarelo. Revista brasileira de sementes, Brasília-DF, v.6, n.2, p. 37-43,1984.

Pizza Júnior, C.T. A cultura do maracujá. São Paulo: Secretaria da Agricultura. Departamento de Produção vegetal. Divisão de Assistência Técnica Especializada, 1966. 102p.

SIMPÓSIO BRASILEIRO SOBRE A CULTURA DO MARACUJAZEIRO, 5., 1998. Jaboticabal. Anais... Jaboticabal : Funep, 1998. 388p.

São José, A.R. Influência do método de extração na qualidade fisiológica de sementes de maracujazeiro amarelo. (Passiflora edulis Sims f. flavicarpa Deg.). 1987. 87f. Tese (Mestrado) Universidade Estadual Paulista, Botucatu.

Thai, Y.T. Storage of passion fruits (Passiflora edulis Sims f. flavicarpa Deg.) seeds. Malays Agriculture Journal, v.51, n.1, p.1823p, 1977.

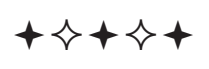

